\title{
Resolution of multiple severe nonsteroidal anti-inflammatory drug-induced colonic strictures with prednisone therapy: A case report and review of the literature
}

\author{
Robert M Penner MD, C Noel Williams FRCP(C) FACP MACG
}

\begin{abstract}
RM Penner, CN Williams. Resolution of multiple severe nonsteroidal anti-inflammatory drug-induced colonic strictures with prednisone therapy: A case report and review of the literature. Can J Gastroenterol 2003;17(8):497-500.

A 69-year-old woman on nonsteroidal anti-inflammatory drugs (NSAIDs) was admitted to a university hospital with abdominal pain, profound anemia and melena stools. Duodenal ulceration and subsequent healing were documented. Colonoscopy revealed haustral ulceration and NSAID-induced colonic diaphragm disease. Discontinuation of NSAID therapy did not result in endoscopic change, but a 20-week course of prednisone was followed by complete resolution. This is the first case describing prednisone monotherapy for such strictures, and only the second in which endoscopic resolution has been documented. With further supporting experience, prednisone may be considered in addition to NSAID discontinuation for patients with this rare but serious complication.
\end{abstract}

Key Words: Anti-inflammatory agents; Colonic diseases; Non-steroidal; Prednisone

$\mathrm{N}$ onsteroidal anti-inflammatory drugs (NSAIDs) are commonly prescribed medications with significant toxicities (1). Although they are best known for gastric and duodenal ulceration, they have also been implicated in the development of colonic complications including ulcerations, colitis-like syndromes and complications of diverticular disease (1). Further evidence links NSAID use to the development of collagenous colitis (2-4).

A rare but serious colonic complication of NSAID use is the formation of diaphragm-like strictures, most commonly in the ascending colon at the site of ulcerated haustra. A paucity of published literature exists on NSAID-associated colonic diaphragms, with only 33 cases reported in the English literature (5-26). Case reports have previously documented symptomatic resolution after the discontinuation of NSAID therapy $(10,12,15,22,26)$, after endoscopic dilation $(19,21)$ or after colonic resection $(7,8,11,13,15-18,23,26)$, but data on followup colonoscopy or radiology after medical or conservative management is available in only five cases $(9,14,15,20,25)$. Complete healing of diaphragms has been documented only once (20).

This single case of complete stricture healing followed an initial attempt at endoscopic dilation and discontinuation of
Guérison de multiples sténoses coliques graves causées par les anti-inflammatoires non stéroïdiens grâce à un traitement par prednisone : Exposé d'un cas et analyse documentaire

Une femme de 69 ans recevant des anti-inflammatoires non stéroïdiens (AINS) a été admise à un hôpital universitaire en raison de douleurs abdominales, d'une anémie profonde et de présence de sang dans les selles. On a observé une ulcération duodénale, qui a par la suite guéri. La colonoscopie a révélé une ulcération haustrale et un diaphragme colique causé par les AINS. L'arrêt du traitement par AINS n'a pas engendré de modifications endoscopiques, mais un traitement de 20 semaines par prednisone s'est traduit par une guérison complète. Il s'agit du premier cas décrit d'une monothérapie par prednisone pour de telles sténoses, et le deuxième seulement pour lequel on a observé une guérison endoscopique. D'autres expériences similaires pourraient servir à appuyer l'utilisation de la prednisone après l'arrêt d'un traitement par AINS chez les patients souffrant de cette complication rare, mais grave.

\footnotetext{
Department of Medicine, Division of Gastroenterology University of Alberta, Edmonton, Alberta

Correspondence and reprints: Dr Noel Williams, 205-27, College Plaza, 8215, 112 Street, Edmonton, Alberta T6G 2 C8.

E-mail nobeco@shaw.ca
}

Received for publication March 10, 2003. Accepted June 3, 2003 


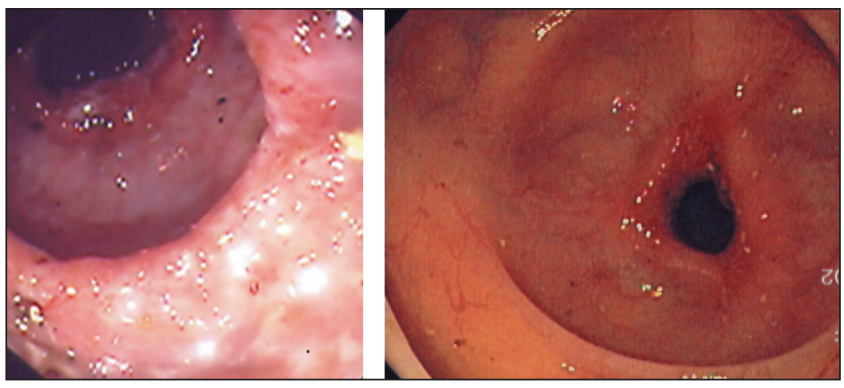

Figure 1) Note the linear ulceration on the haustral ridges as a precursor for colonic strictures

acid (ASA) daily, and two to four tablets of Arthrotec (Pharmacia, Canada; $50 \mathrm{mg}$ of enteric-coated diclofenac sodium and $200 \mu \mathrm{g}$ of misoprostol per tablet) per day. She had been taking these medications in similar dosage for many years. She reported having been investigated at another centre for a single episode of bright red blood per rectum approximately seven years previously. That episode had been attributed to hemorrhoids after she had an otherwise normal colonoscopy. There was no other history of gastrointestinal illness. She had never received radiation therapy and had no family history of inflammatory bowel disease or colon cancer.

Laboratory investigations included a complete blood count that revealed a low hemoglobin concentration of $39 \mathrm{~g} / \mathrm{L}$ with a mean corpuscular volume of $69 \mathrm{fL}$, a platelet count elevated at $622 \times 10^{9} / \mathrm{L}$ and a white blood cell count elevated at $15.8 \times 10^{9} / \mathrm{L}$. Her creatinine, electrolytes, liver enzymes and blood clotting times were normal.

Gastroduodenoscopy and colonoscopy were carried out on April 21, 2002, and April 25, 2002, respectively. Gastroscopy revealed a diffusely erythematous antrum and body, which were biopsied and found to be histologically normal with no evidence of Helicobacter pylori. On duodenoscopy, four ulcers were found, three of which were clean-based and approximately $1 \mathrm{~cm}$ in diameter. The fourth was $3 \times 1 \mathrm{~cm}$ in size and had a central elevation but no visible vessel. Her colonoscopy revealed small focal haustral ulcerations and a few diverticuli in the sigmoid colon. The transverse colon was affected by severe circumferential ulcerations limited to the haustra with intervening normal mucosa. Five consecutive haustra were notable for circumferential diaphragmatic narrowings of the lumen to approximately $1.5 \mathrm{~cm}$ in diameter (Figure 1). The colonoscope could be just passed through the strictures and the ascending colon was endoscopically normal. Biopsies taken from her colonic ulcers showed ulcers lined by acute inflammatory exudates, consistent with ischemic injury and possibly related to NSAID use. No features of malignancy or Crohn's disease were seen. A small bowel follow-through revealed no other strictures.

During her course in hospital, she was given blood transfusions and oral iron therapy for her anemia, treated with two $40 \mathrm{mg}$ tablets of pantoprazole sodium per day for her duodenal ulcers, and given $4 \mathrm{~g} /$ day of 5 -aminosalicylic acid in an attempt to accelerate healing of her colonic lesions. ASA and arthrotec were discontinued and her musculoskeletal pain was managed with acetaminophen, glucosamine sulfate and physiotherapy. Her abdominal pain was still present after meals, but its location became more periumbilical. For this reason, repeat gastroduodenoscopy and colonoscopy were performed on May 2, 2002. Her duodenum at this time had some residual areas

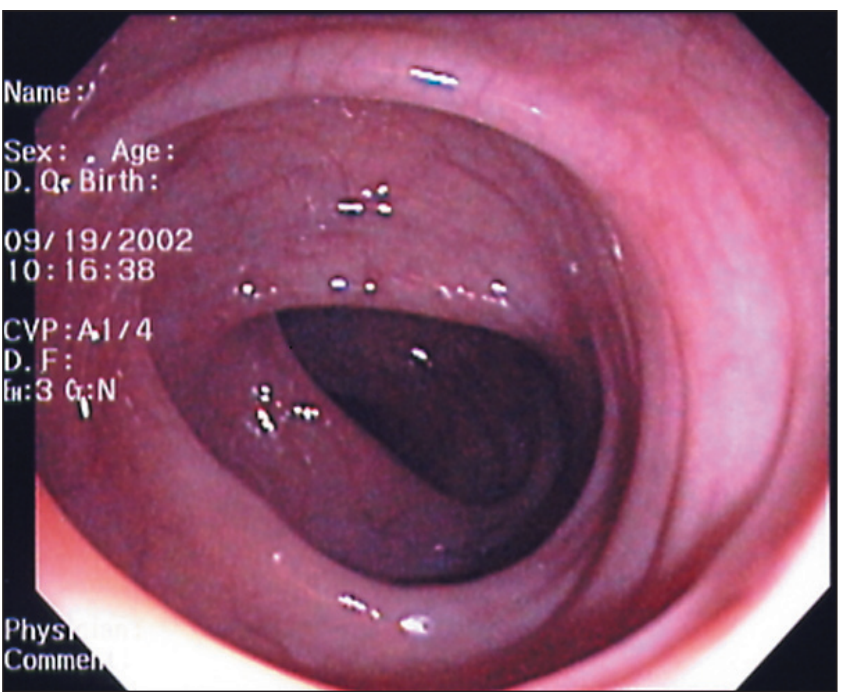

Figure 2) Healed transverse colon following a 20-week course of prednisone therapy

of inflammation but there was no ulceration present. Colonoscopy and biopsies of her colonic lesions were essentially unchanged.

Because her duodenal lesions had resolved with no obvious change of her colonic lesions, 5-aminosalicylic acid treatment was discontinued and an empiric course of prednisone was given at an initial dose of $40 \mathrm{mg}$ per day. She was discharged to a convalescent hospital and given intensive rehabilitation in preparation for knee replacement surgery. Because her lower abdominal pain was still present and elective surgery was planned, a repeat colonoscopy was performed May 15. At this time, only two weeks after the initiation of prednisone, her symptoms had improved and there was already significant healing of her colopathy. The left colon was observed to be normal and the strictures of her transverse colon were diminishing. The ascending colon remained normal. Prednisone treatment was decreased to $30 \mathrm{mg}$ per day for two weeks, then $20 \mathrm{mg}$ per day, a dose that was considered safe for her to take perioperatively.

The patient had her knee replacement surgery with further physiotherapy and remained on prednisone $20 \mathrm{mg}$ per day. As the optimal duration of therapy with prednisone was unknown, it was decided to repeat colonoscopy after approximately 17 weeks, a duration adequate to induce healing of other causes of colonic inflammation such as Crohn's disease. After 20 weeks of prednisone therapy, her colonoscopy was entirely normal and there was no trace of her previous ulceration or stricturing (Figure 2). Her hemoglobin had risen since her initial hospitalization and she required no transfusion at the time of her knee replacement. She had no further evidence of gastrointestinal bleeding and had begun regaining the weight she had lost. Her prednisone, which had been taken with no significant side effects, was tapered and discontinued.

\section{DISCUSSION}

Colonic diaphragm formation is a rare and poorly understood side effect of NSAID use that can have serious consequences. Many NSAIDs have been associated with this complication, but most followed the introduction of extended-release NSAIDs and a disproportionate number have occurred with enteric-coated diclofenac preparations $(1,21,25)$. Chronic 
TABLE 1

\begin{tabular}{lc}
$\begin{array}{l}\text { Symptoms and signs prompting investigation in patients } \\
\text { with nonsteroidal anti-inflammatory drug-induced colonic } \\
\text { strictures }\end{array}$ \\
\hline Symptom or sign & Cases (\%) \\
\hline Anemia & $20(61)$ \\
Abdominal pain & $14(42)$ \\
Diarrhea & $8(24)$ \\
Weight loss & $6(18)$ \\
Anorexia & $4(12)$ \\
Nausea \pm vomiting & $4(12)$ \\
Constipation & $2(6)$ \\
Frank hematochezia & $1(3)$ \\
Perforated viscus & $1(3)$ \\
Abdominal mass & $1(3)$ \\
\hline
\end{tabular}

$n=33$. Data from references 5 to 26

NSAID-induced colonic ulceration may persist because of antibodies to cyclooxygenase, or the influence of bile acids, bacteria, food antigens or neutrophil chemoattractants (1). Of the 33 previously published cases in the English literature $(5-26)$, the clinical and laboratory features that prompted investigation most often are listed in Table 1 . They were most frequent in the right colon (Table 2). The differential diagnosis for the strictures includes Crohn's disease and colon cancer.

Data are scarce on the management and follow-up of this condition. Publications on eight of the 33 previous cases provide no details on treatment or follow-up $(5,12,24)$. Twelve cases were managed with surgical resection $(7,8,11,13,15$ 18,23,26); four with endoscopic dilation (19-21) and nine were managed conservatively by discontinuing NSAID therapy as the sole therapeutic maneuver $(6,9,10,12,14,15,22,25)$.

Surgical resection has been a successful but dramatic method of dealing with these lesions. Of 12 cases, nine had no further complications after resection and discontinuation of NSAID therapy $(8,11,13,15-17,23)$. The remaining three patients resumed NSAID use and experienced new stricture formation $(7,18,26)$. One of these had partial improvement with endoscopic dilation of the new strictures (18) but another failed treatment with endoscopic dilation and required further resection (26).

Of the four cases managed with endoscopic dilation of strictures (19-21), three had symptomatic improvement but no endoscopic follow-up $(19,21)$. The remaining patient continued having abdominal pain for three months and at that time received repeat dilation and treatment with prednisone (20). In this case, prednisone was administered at an initial dose of $40 \mathrm{mg}$ per day with a $5 \mathrm{mg}$ taper each week, and complete endoscopic healing was documented following this eight-week therapy (20).

Of the nine patients managed conservatively by discontinuing NSAID therapy, one had no follow-up (6), three became asymptomatic and had no further follow-up $(10,12,22)$, four had endoscopic or radiological follow-up indicating no change to the lesions (after two weeks, five weeks, 18 months and two years, respectively) $(9,14,15,25)$ and one developed an obstruction relating to the lesion after three months of follow-up (12).

With the limited data available, discontinuing NSAIDs seems to be an obvious first step in patients who develop colonic strictures secondary to the use of this medication. This is supported by the fact that two patients went on to require surgery due to complications of restarting NSAIDs $(18,26)$.
TABLE 2

Locations of nonsteroidal anti-inflammatory drug-induced colonic strictures

\begin{tabular}{lc}
\hline Location & Cases (\%) \\
\hline Right colon only & $26(79)$ \\
Right and transverse colon & $4(12)$ \\
Left colon only & $1(3)$ \\
Left and transverse colon & $1(3)$ \\
Transverse colon only & $1(3)$ \\
\hline
\end{tabular}

$n=33$. Data from references 5 to 26

Beyond that, the advice to give patients is not as clear. While surgical resection has been successful, it has significant risks that could be avoided by using medical therapy. Discontinuing NSAIDs alone or in combination with endoscopic dilation has often resulted in symptomatic improvement but has never resulted in healing of lesions on follow-up.

Our choice to use empirical prednisone therapy in this patient was guided by previous animal studies demonstrating that NSAIDs induce acute and chronic inflammatory changes in the intestine, some of which may be attenuated by corticosteroids (27). We were also guided by a previous anecdotal experience of a 49-year-old woman who had been treated with steroids for ascending colonic ulceration thought initially to be Crohn's disease. Subsequent biopsies revealed that her lesions were NSAID-related, but the lesions healed completely after requiring several months of steroid therapy.

Corticosteroids have also had beneficial effects when used intralesionally for strictures elsewhere in the gastrointestinal tract (28-30). In the esophagus, these benefits seem to occur regardless of the initial cause of stricture formation (28).

In the present case, an oral loading dose was used, followed by a maintenance dose for four and a half months, resulting in complete healing. The dosing regimen was adapted from that used to induce remission of active Crohn's disease.

\section{CONCLUSIONS}

The literature available demonstrates that patients left with unhealed strictures can develop severe consequences in the form of obstruction or later requirement for surgical therapy $(12,26)$. Furthermore, the follow-up of patients treated conservatively or endoscopically generally reveals no change in their lesions $(9,14,15,25)$. The only previously published case of endoscopic resolution of NSAID-induced colonic strictures followed prednisone therapy after colonic dilation (20), and the case presented here is a successful first trial of prednisone monotherapy. Further experience, and optimally larger studies, with the use of prednisone for NSAID-induced colonic strictures is required to confirm an optimal management strategy, but this case and the previous literature suggest that prednisone can be considered in addition to NSAID discontinuation with or without endoscopic dilation for the management of NSAID-induced colonic diaphragm disease.

\section{REFERENCES}

1. Bjarnson I, Hayllar J, Macpherson AJ, et al. Side effects of nonsteroidal anti-inflammatory drugs on the small and large intestine in humans. Gastroenterology 1993;104:1832-47.

2. Riddell RH, Tanaka M, Mazzoleni G. Non-steroidal anti-inflammatory drugs as a possible cause of collagenous colitis:

A case-control study. Gut 1992;33:683-6. 
3. Giardello FM, Hansen C, Lazenby AJ, et al. Collagenous colitis in the setting of nonsteroidal anti-inflammatory drugs and antibiotics. Dig Dis Sci 1990;35:257-60.

4. Tanner AR, Raghunath AS. Colonic inflammation and nonsteroidal anti-inflammatory drug administration. Digestion 1988;41:116-20.

5. Sheers R, Williams WR. NSAIDs and gut damage. Lancet 1989;ii: 1154.

6. Huber T, Ruchti C, Halter F. Nonsteroidal anti-inflammatory druginduced colonic strictures: A case report. Gastroenterology 1991;100:1119-22.

7. Monahan DW, Starnes EC, Parker AL. Colonic strictures in a patient on non-steroidal anti-inflammatory drugs. Gastrointest Endosc 1992;38:385-8.

8. Fellows IW, Clarke JMF, Roberts PF. Non-steroidal anti-inflammatory drug-induced jejunal and colonic diaphragm disease: A report of two cases. Gut 1992;33:1424-6.

9. Haque S, Haswell JE, Dreznick JT, et al. A cecal diaphragm associated with the use of nonsteroidal anti-inflammatory drugs. J Clin Gastroenterol 1992;15:332-5.

10. Whitcomb DC, Martin SP, Trellis DR, et al. 'Diaphragmlike' stricture and ulcer of the colon during diclofenac treatment. Arch Intern Med 1992;152:2341-3.

11. Pucius RJ, Charles AK, Adair HM, Rowe RC, Hacking JC. Diaphragm-like strictures of the colon induced by nonsteroidal antiinflammatory drugs. Br J Surg 1993;80:395-6.

12. Halter FH, Weber B, Huber T, Eigenmann F, Frey MP, Ruchti C. Diaphragm disease of the ascending colon. Association with sustained-release diclofenac. J Clin Gastroenterol 1993;16:74-80.

13. Robinson MHE, Wheatley T, Leach IH. Nonsteroidal antiinflammatory drug-induced colonic stricture. An unusual case of large bowel obstruction and perforation. Dig Dis Sci 1995;40:315-9.

14. Nicholson AA, Bennett JR. Case report: Radiological appearance of colonic stricture associated with the use of nonsteroidal antiinflammatory drugs. Clin Radiol 1995;50:268-9.

15. Gargot D, Chaussade S, d'Alteroche L, et al. Nonsteroidal antiinflammatory drug-induced colonic strictures: Two cases and literature review. Am J Gastroenterol 1995;90:2035-8.

16. Kaufman HL, Fischer AH, Carroll MC, Becker JM. Colonic ulceration associated with nonsteroidal anti-inflammatory drugs. Report of three cases. Dis Colon Rectum 1996;39:705-10.

17. Hooker GD, Gregor JC, Ponich TP, McLarty TD. Diaphragm-like strictures of the right colon induced by indomethacin suppositories: Evidence of a systemic effect. Gastrointest Endosc 1996;44:199-202.

18. Eis MJ, Watkins BM, Philip A, et al. Nonsteroidal-induced benign strictures of the colon: A case report and review of the literature. Am J Gastroenterol 1998;93:120-1.

19. Gopal DV, Katon RM. Endoscopic balloon dilation of multiple NSAID-induced colonic strictures: Case report and review of the literature on NSAID-related colopathy. Gastrointest Endosc 1999;50:120-3.

20. Weinstock LB, Hamoud Z, Brandwin L. Nonsteroidal antiinflammatory drug-induced colonic stricture and ulceration treated with balloon dilatation and prednisone. Gastrointest Endosc 1999;50:564-5.

21. Smith JA, Pineau BC. Endoscopic therapy of NSAID-induced colonic diaphragm disease: Two cases and a review of published reports. Gastrointest Endosc 2000;52:120-5.

22. Kehrer G, Bosseckert H, Koppe P, et al. Unusual negative side effects of nonsteroidal anti-inflammatory drugs in the proximal colon. Z Gastroenterol 2000;38:499-503.

23. Israel LH, Koea JB, Stewart ID, Wright CL, Frankish PD. Nonsteroidal anti-inflammatory drug-induced strictures of the colon. Report of a case and review of the literature. Dis Colon Rectum 2001;44:1362-4.

24. Püspök A, Kiener H-P, Oberhuber G. Clinical, endoscopic, and histologic spectrum of nonsteroidal anti-inflammatory drug-induced lesions in the colon. Dis Colon Rectum 2000;43:685-91.

25. Kurahara K, Matsumoto T, Iida M, et al. Clinical and endoscopic features of nonsteroidal anti-inflammatory drug-induced colonic ulcerations. Am J Gastroenterol 2001;96:473-9.

26. Spirnak JP. Colonic diaphragms associated with long-term use of nonsteroidal antiinflammatory drugs. Am J Radiol 1993;160:1148-9.

27. Yamada T, Deitch E, Specian RD, Perry MA, Santor RB, Grisham MB. Mechanisms of acute and chronic intestinal inflammation induced by indomethacin. Inflammation 1993;17:641-62.

28. Kochhar R, Makharia GK. Usefulness of intralesional triamcinolone in treatment of benign esophageal strictures. Gastrointest Endosc 2002;56:829-34.

29. Rupp T, Earle D, Ikenberry S, et al. Randomized trial of Savary dilation with/without intralesional steroids for benign gastroesophageal reflux strictures. Gastrointest Endosc 1995;41:357. (Abst)

30. Kochhar R, Sriram PVJ, Ray JD, et al. Intralesional steroid injections for corrosive induced pyloric stenosis. Endoscopy 1998;30:734-6. 


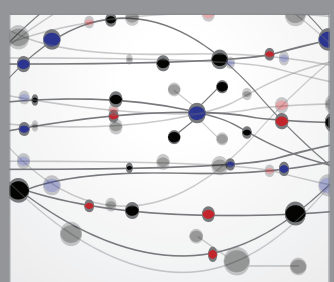

The Scientific World Journal
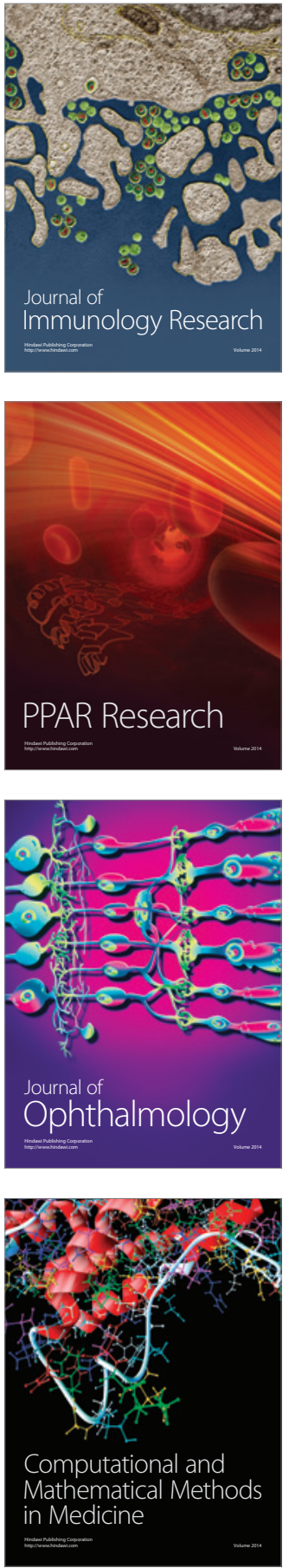

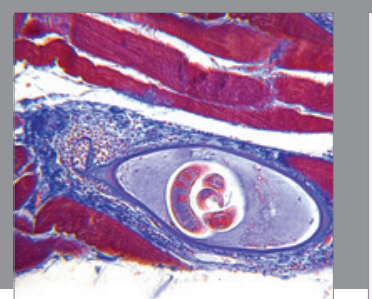

Gastroenterology Research and Practice

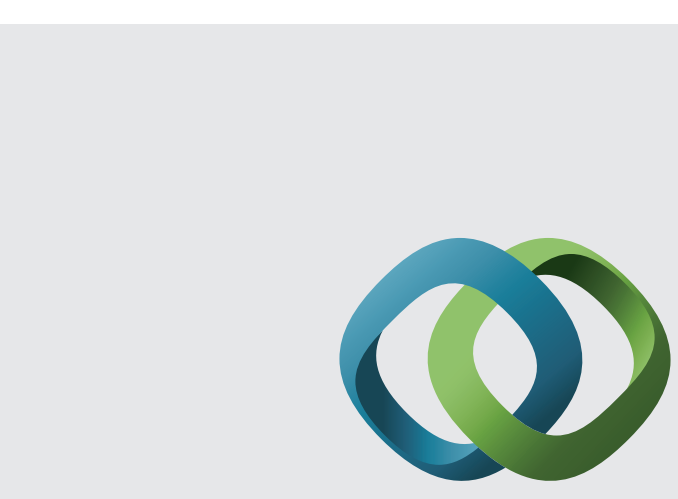

\section{Hindawi}

Submit your manuscripts at

http://www.hindawi.com
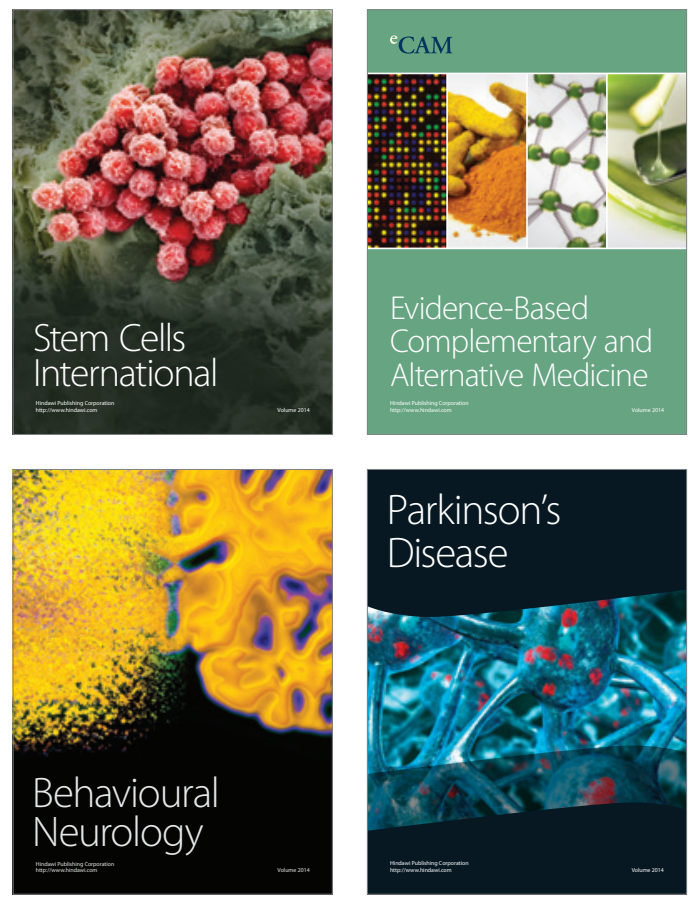
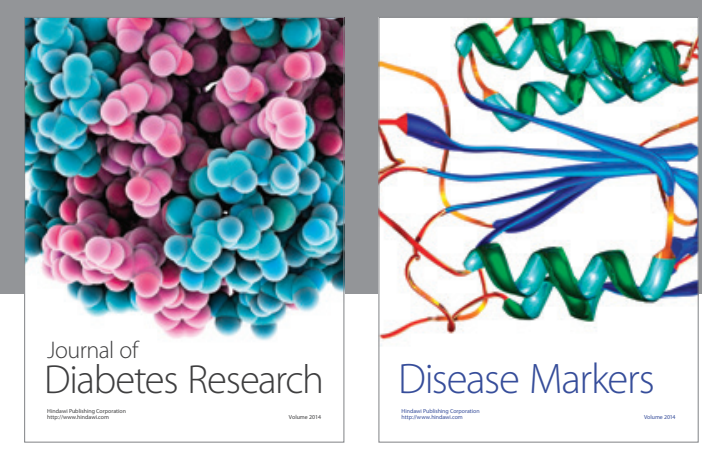

Disease Markers
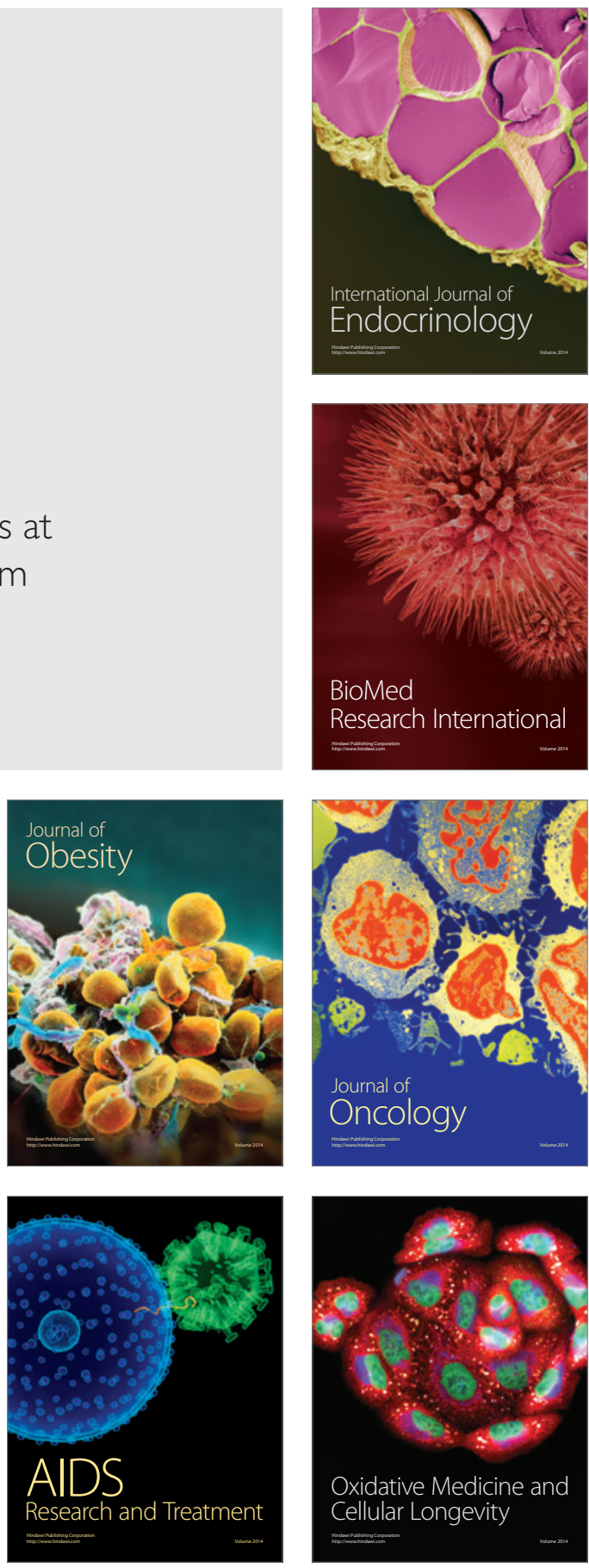